\title{
On the estimation of the bed-material transport and budget along a river segment: application to the Middle Loire River, France
}

\author{
B. Camenen ${ }^{1 *}$, R.C. Grabowski², A. Latapie ${ }^{1}$, A. Paquier ${ }^{1}$, \\ L. Solari ${ }^{3}$, and S. Rodrigues ${ }^{4}$ \\ ${ }^{1}$ Irstea Lyon, 5 rue de la Doua CS70077, 69626 Villeurbanne, France \\ ${ }^{2}$ Cranfield Water Science Institute, Cranfield University, United Kingdom \\ ${ }^{3}$ Dept. of Civil and Environmental Engineering, University of Florence, Italy \\ ${ }^{4}$ F. Rabelais University, E.A. 6293 GéHCO, 37200 Tours, France \\ * Corresponding author, E-mail: benoit.camenen@irstea.fr \\ Tel. +33 (0)472 208626 ; Fax +33 (0)4 78477875
}

\begin{abstract}
Sediment load and budgets are a fundamental component of the process-based hydromorphological framework developed by the REFORM project, and are needed to accurately assess the current condition of a river, its sensitivity to change, and its likely future evolutionary trajectory. This paper presents an evaluation of three different methods for estimating both bedload sediment transport and bed-material budget within river channels, using the Middle Loire River as a case study. The first method is based on the stream power concept and does not need any hydraulic calculations. It yields estimates of the sediment transport in the same order of magnitude as measurements but poor results for the bed-material budget in terms of magnitude and tendency. For the second method, hydraulic parameters are computed using the Manning-Strickler equation (or a 1D hydraulic model for steady flow). It provides useful indicators for understanding river dynamics but does not yield significant improvements compared to the first method. The third method uses 1D numerical software for water flow and river bed evolution. It yields the most accurate results for both sediment transport and bed evolution but requires more data and overall more work to construct the model. Guidance is provided on the amount of data required, the competence needed to build the models, and the predictive capability of each of the methods.
\end{abstract}

Keywords: sediment transport, sediment budget, bed material, 1D modelling. 


\section{Introduction}

An understanding of sediment transport and budgets is essential for the sustainable management of river systems. The quantity, dynamics and grain size of sediment delivered to and transported within rivers has a controlling influence on river planform type (e.g. meandering, wandering, braided), the presence and type of depositional features in the channel and floodplain (e.g. bars, levees, etc.), the lateral connectivity of rivers and floodplains, and the likely future trajectories of geomorphic change in the system (e.g. Surian and Rinaldi, 2003). The ecosystems that are dependent on the natural hydrological and geomorphological functioning of rivers are negatively impacted by the altered sediment dynamics though, for example, the loss of physical habitat and changes to bed levels and water tables (Pitlick and Wilcock, 2001). Consequently, river restoration and management are beginning to move beyond physical habitat reconstruction of individual reaches towards process-based approaches that expressly consider water and sediment dynamics within a catchment.

Sediment transport is a key component of the process-based hydromorphological assessment framework proposed by the REFORM project, which aims to improve the science underlying the links between hydromorphology and ecology to support costeffective implementation of restoration measures and monitoring in line with the Water Framework Directive (Gurnell et al., 2014; Gurnell et al., 2015). The framework using a hierarchical approach to investigate how flows of water and sediment in a catchment cascade down to produce channel features and river styles at the reach scale. It is a flexible approach that outlines the key information needed to assess the current hydromorphological condition and sensitivity of a reach, and to explore future evolution under different management and climate change scenarios. Aspects of sediment production and transport are included at every spatial scale of the framework, but are particularly important at the segment scale for sediment transport within the river channel. Whilst empirical methods exist to measure sediment transport and estimate budgets (for a recent review, see Grabowski et al., 2014), a general lack of long-term monitoring data for most rivers means that sediment transport and budget models are the preferred, and often only, approach available.

The classic method to estimate sediment budgets involves two steps (Reid and Dunne, 1996). The first step consists of the estimation of sediment input to the river. Methods are generally based on GIS using interpretation of aerial photographs and fieldwork analysis to evaluate sediment production from hillslopes. The second step consists of an estimation of the sediment transport, erosion and storage in channels based on the channel geometry, flow and sediment characteristics. Then, the sediment budget in a specific reach is calculated in an individual reach by differencing the sediment input and sediment output. A sediment budget can also be based on repeat channel surveys (Brewer and Passmore, 2002), but such method implies a detailed data set that is often costly and difficult to apply on long reaches. And of course, it can only assess past evolutions, not predict future changes.

Due to the routine absence of field data, sediment transport within the channel (step

2 ) is often estimated using empirical formulae for bed-material load, transported as bedload and suspended load. Large discrepancies may be observed using one or another 
formulae and, when possible, the choice or calibration of an empirical formula should be made together with minimum oriented field surveys (Wilcock, 2001). This approach is limited to non-cohesive sediment, as its transport is related to local dynamics, and is not applicable for fine sediment transported as washload. However, recent work by Grabowski and Gurnell (2015) have shown how fine sediment can induce channel change in a gravel-bed system.

One of the challenges of using sediment transport models in a process-based assessment of hydromorphology is knowing which model to use. Whilst the choice of model is often determined by the availability of data (e.g. sediment loads, particle size, bathymetry, etc.), the outputs of the modelling may not be relevant to the aim of the study or for applications to river management. This paper aims to provide guidance to scientists and managers on the different types of models that can be used to quantify sediment transport and budgets. It describes the three main methods for estimating bed-material transport and budget, in order of increasing complexity, from a rough estimation of stream power to full 1D numerical modelling. The models are then applied to a long sandy-gravelly river segment, i.e. several hundreds of $\mathrm{km}$ : the Middle Loire River, France, to inform a discussion on the limitations and advantages of each of these methods to compute sediment transport and sediment budgets depending on the data available.

\section{Methods to estimate sediment transport and bud- get}

A basic and fundamental question in fluvial geomorphology is whether a reach is in equilibrium or is undergoing net incision or deposition. As discussed above, models are often used to estimate bed-material transport along the river using semi-empirical formulae. Three different methods are presented in this section in increasing order of complexity: stream power, Manning-Strickler, and 1D hydraulic and bed evolution.

\section{$2.1 \quad$ Stream power method}

The simplest way to estimate sediment transport is the stream power method, which is widely used in geomorphological research (Bagnold, 1966; Parker et al., 2014):

$$
\omega=\tau U \approx \rho g \frac{Q S}{W} \approx \rho g \frac{Q S_{b}}{B}
$$

where $\tau$ and $U$ are the section-averaged bed shear stress and velocity, $\rho$ is the the density of water, $Q$ the water discharge, $g$ the acceleration of gravity, and the energy slope $S$ and the river width $W$ are assumed to be equal to the river bed slope $S_{b}$ and active width $B$, respectively. The main advantage of this method is that it does not need any hydraulic parameter to be computed.

Then, some Bagnold (1966) type formula (names hereafter Bm) can be applied. 
For bedload transport, it is written here in a dimensionless form:

$$
Q_{s}=\frac{\epsilon_{b} B(s-1)}{\rho g \tan \phi}\left(\omega-\omega_{c r}\right)
$$

with $s$ the sediment relative density, $\tan \phi$ the ratio of tangential to normal shear force, $\omega_{c r}$ the critical stream power for inception of sediment transport (Camenen, 2012) and $\epsilon_{b} \approx 0.02$ is the bedload efficiency, which can be assumed constant as a first estimation.

Once sediment transport is calculate for a specific water discharge, it is possible to estimate yearly averaged volume of sediment transported across a specific section using the flow duration curve and applying the following equation:

$$
V_{t}=\sum_{i=1}^{n} Q_{s}\left(Q_{i}\right) D_{i}
$$

where $Q_{i}$ corresponds to a discharge, which is statistically observed during the duration $D_{i}$ per year, and $n$ is the number of classes for describing the flow duration curve.

Then, a simple method to estimate the sediment budget involves calculating yearly averaged sediment transport volumes for each sub-reach and apply the mass conservation equation:

$$
\Delta V_{j}=V_{t, j+1}-V_{t, j}+V_{l a t}
$$

where $V_{t}$ is the volume transported, subscripts $j$ and $j+1$ stand for the studied reach and the reach located upstream, respectively, $V_{\text {lat }}$ corresponds to possible lateral inputs from tributaries or bank erosion. This method will be named "model 1" hereafter.

\subsection{Manning-Strickler method}

To calculate stream power more accurately, better estimates of hydraulic parameters are needed, and more specifically bed shear stress:

$$
\tau=\rho g R_{h} S
$$

where $R_{h}$ is the hydraulic radius. Since aspect ratios (ratio of width over average flow depth) are typically much larger than $1, R_{h}$ can be safely approximated with the mean water depth $H$, and the Manning Strickler equation can be used assuming a rectangular cross-section: $H \approx\left[Q /\left(B K S_{b}^{1 / 2}\right)\right]^{3 / 5}$ if $B \gg H$ with $K$ the total Strickler coefficient. One important difficulty remains the estimation of $K$ for a specific reach. The use of 1D hydraulic model for steady conditions would minimize the uncertainty on $K$ or $\tau$ by adjusting resistance coefficients in order to obtain a suitable reproduction of the measured water levels available.

However, one should be careful on the application of the computed bed shear stress. The mean bed shear stress $\tau$ is the sum of the stresses acting on the bed and banks due to the friction attributable to the grains themselves, i.e. skin friction $\left(\tau_{s f}\right)$, the resistance created by the presence of bed forms, i.e. form drag $\left(\tau_{f d}\right)$, and the additional resistance due to bank effect, river sinuosity, etc., i.e. side drag $\left(\tau_{s d}: \tau=\tau_{s f}+\tau_{f d}+\tau_{s d}\right.$. 
Bed forms may impact the ability of the flow to transport sediment and should ideally be included (Frings and Kleinhans, 2008; Francalanci et al., 2012). According to MeyerPeter and Müller (1948), the effective shear stress, which is the part responsible for transporting sediment, can be estimated using the relationship: $\tau_{\text {eff }}=\left(K / K_{s}\right)^{3 / 2} \tau$ where $K_{s}$ is the grain related Strickler coefficient.

As soon as $\tau$ (or $\tau_{\text {eff }}$ ) is computed, one can apply the Bm formula using $\omega=\tau U$ as well as any adapted sediment transport formula based on the bed shear stress concept. In this paper, we will use the Camenen and Larson (2005) bedload formula (named CL hereafter), which is similar to the Meyer-Peter and Müller (1948) formula (named hereafter MPM) apart from the consideration of the critical bed shear stress.

$$
Q_{s}=12 B \sqrt{(s-1) g d_{j}^{3}} \theta^{3 / 2} \exp \left(-4.5 \frac{\theta_{c r}}{\theta}\right)
$$

where $\theta=\tau /\left[\left(\rho_{s}-\rho\right) g d_{50}\right]$ is the Shields parameter or dimensionless bed shear stress, and $\theta_{c r}$ its critical value for inception of transport estimated from the Shields curve.

The sediment budget can be estimated using the same methodology as for "model 1". This method will be named "model 2" hereafter (2a if a 1D hydraulic model is used, $2 \mathrm{~b}$ if the Manning-Strickler equation is applied).

\subsection{D hydraulic and bed evolution modelling}

A full 1D hydraulic model generally solves the Barré-de-St-Venant equations allowing computation for unsteady flows (using the discharge time series for a specific period). Bed evolution is usually solved using the following equation for mass conservation:

$$
(1-p) \frac{\partial A_{s}}{\partial t}+\frac{\partial Q_{s}}{\partial x}=q_{s, l a t}
$$

where $p$ is the porosity of the bed material, $A_{s}$ the solid section area, $Q_{s}$ the sediment transport in the section following the flow direction and $q_{s, l a t}$ stands for the lateral sediment inputs.

Sediment transport formulae such as Eqs. 2 or 6 are based on an equilibrium state and so provide a sediment transport capacity $Q_{s *}$. However, the adaptation to the equilibrium state may not be immediate. Daubert and Lebreton (1967) proposed to use the following non-equilibrium model :

$$
\frac{\partial Q_{s}}{\partial x}=\frac{Q_{s *}-Q_{s}}{L_{a}}
$$

with $L_{a}$ the adaptation length. In natural rivers and for 1D modelling, $L_{a}$ is generally given large values corresponding to several widths of the river or mesh sizes (Wu et al., 2004; El Kadi Abderrezzak and Paquier, 2009).

There exist many numerical codes (see Papanicolaou et al., 2008, for a list of selected $1 \mathrm{D}$ codes). For the purpose of this study, the model RubarBE, developed by Irstea (El Kadi Abderrezzak and Paquier, 2009) was used. This method will be named "model 3" hereafter. 


\section{Application on the Middle Loire River}

\subsection{Site description}

The Loire River is the longest river in France with a length of $1012 \mathrm{~km}$ and a drainage area of $117000 \mathrm{~km}^{2}$. The Middle Loire River is $450 \mathrm{~km}$ long and flows from the confluence with the Allier River to the confluence with the Maine River (Fig. 1). Following the REFORM framework (Gurnell et al., 2014), the river was subdivided into three segments at the confluences of the Cher and Vienne rivers due the large increases in catchment area. The Middle Loire River is characterized by a a multi-thread planform in the upstream segment, a meandering planform in the short middle segment, and a multi-thread channel with numerous vegetated islands and sand bars in the downstream segment. A more detailed presentation of the study site as well as a delineation in 167 homogeneous reaches are provided in Latapie et al. (2014).

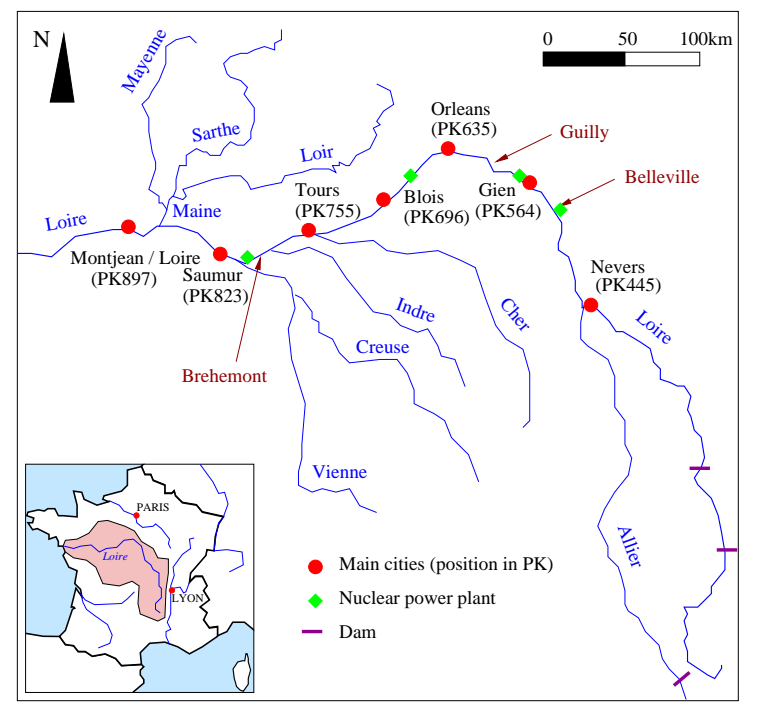

Figure 1: Location map showing the study area and the three reference sites (Belleville, Guilly, and Bréhémont); the study segments lies from Nevers to Montjean.

Three reference sites have been chosen to cover the different configurations of the Middle Loire River and discuss model results with experimental data (bathymetric data mainly, Fig. 1): the Belleville site is about $37 \mathrm{~km}$ long and highly anthropogenized (bed evolution data from 1996 to 1998); the Guilly site is $25 \mathrm{~km}$ long and characterised by some meanders, with bed evolution data from 1995 to 2008; and finally, the Bréhémont site is $13 \mathrm{~km}$ long with sand bars and multiple channels (bed evolution data from 2000 to 2002). They include 7, 4, and 3 homogeneous reaches, respectively. More details on these sites are provided in Latapie (2011).

\subsection{Longitudinal description of the grain size characteristics}

Estimates of median grain size $\left(d_{50}\right)$ of the river bed material were obtained from the DREAL Centre based on samples collected in the main channel between 1970 and 
2008, as well as from a recent survey that characterised grain size in the main channel (Valverde et al., 2013). Large uncertainties exist in the estimation of the longitudinal variation of the grain size mainly due to the definition of a single river bed material grain size, however a significant vertical and transversal variability was observed. A downstream fining exponential law in the form of the Sternberg (1875) formulation was first adopted to extrapolate data to the whole segment (Fig. 2b):

$$
d_{50}=d_{50(x=0)} \exp (-a x)
$$

with $d_{50}$ the river bed material median grain size at a distance $x$ from upstream, $d_{50(x=0)}$ the river bed material median grain size measured upstream $\left(d_{50(x=0)}=4.4 \mathrm{~mm}\right)$ and $a$ a coefficient $\left(a=4.65 \times 10^{-6} \mathrm{~m}^{-1}\right.$ in our case $)$.

(a)

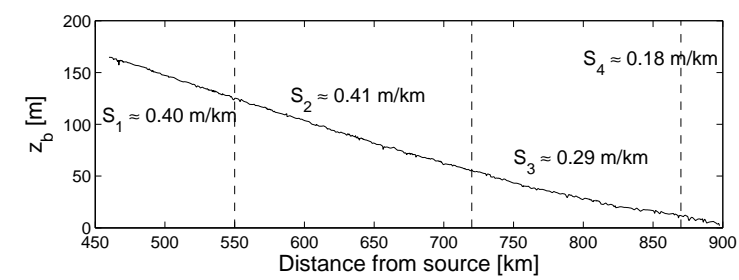

(b)

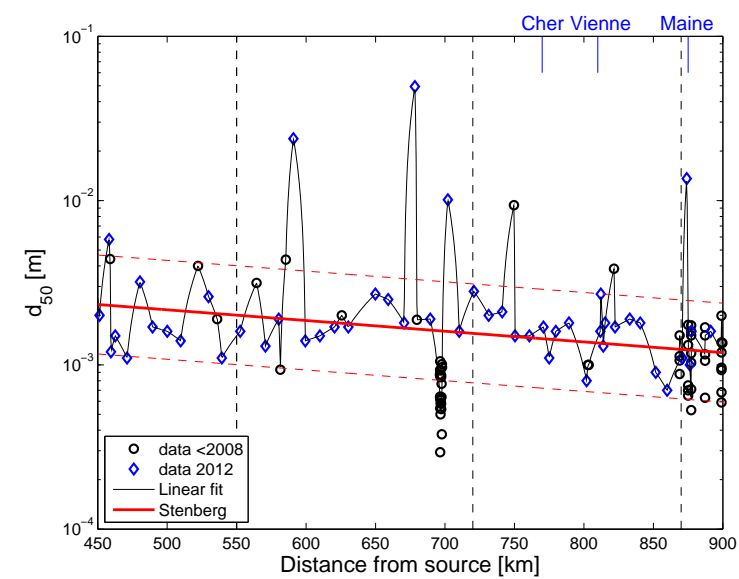

Figure 2: Longitudinal profile and slope of the Middle Loire River (a) and downstream variation in median grain size for the main channel (vertical lines correspond to delineation of four geological units (Latapie et al., 2014)).

As observed in Fig. 2, there is a significant scatter and a general lack of data. The proposed downstream variation of the grain size either using the multi-linear fit or the exponential fit is thus imprecise. Sediments of the Middle Loire River are mainly made of coarse sands (Fig. 2b).

Although one could expect sand to be carried as suspended load, bedload was observed to prevail on the morphodynamics (Claude et al., 2012). The few suspended load measurements available (at Bréhémont) indicate that it is of the same order of magnitude as bedload during flood events but lower for medium discharges. We will assume in this paper that bedload is prevailing. However, one should note that the proposed methodology can also be applied when graded suspension cannot be neglected. In this case, a total sediment transport formula needs to be employed. 


\subsection{Hydraulic description and bedload estimation}

The impact of the models on the estimation of reach-averaged hydraulic parameters and bedload transport is presented in Fig. 3 for a section of the Loire River, next to Bréhémont, where many hydro-sedimentary measurements have been made (Claude et al., 2012). The 1D hydraulic model (model 2a) yields quite accurate results for section averaged parameters as soon as they are properly calibrated (Fig. 3a). The Manning-Strickler equation (MS eq. or model 2b) yields poorer results for the section averaged velocity since the description of the section is extremely simplified and the absence of calibration may easily result to an error of $\pm 10 \%$ (Fig. 3a).

(a)

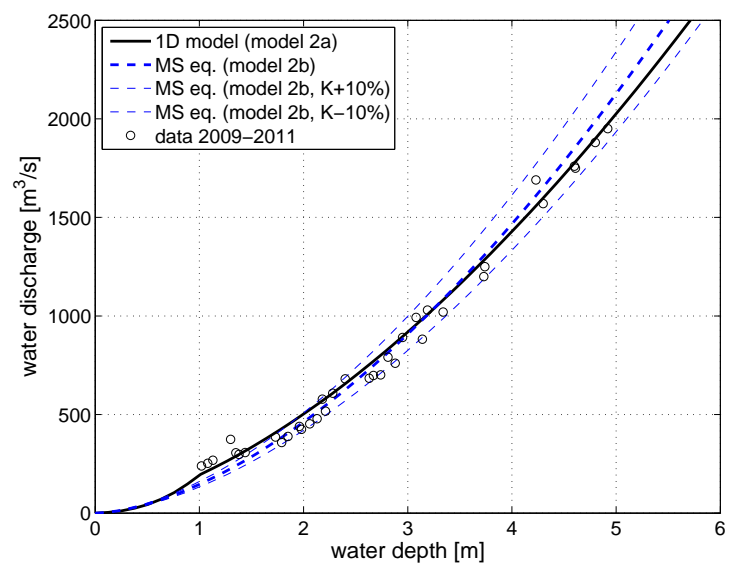

(b)

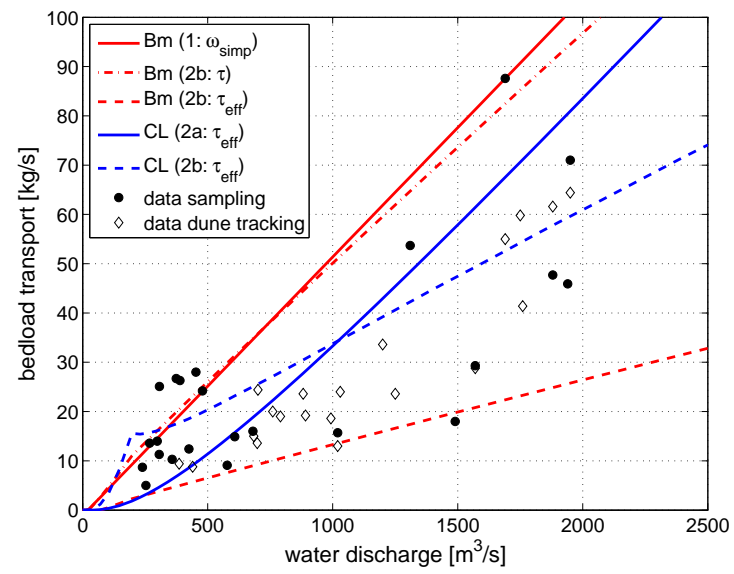

Figure 3: Estimation of the hydraulic parameters (a) and bedload transport (b) using simple models (model 1: simplified estimation of the stream power; model 2a: rating curve (1D model); model 2b: Manning-Strickler (MS) law with a rectangular section (data collected on the site of Bréhémont).

When the results for bedload transport (estimated using the CL formula) are compared, a wide divergence is apparent between the different methods. However, the results for the different models are all comparable to the scatter observed in the collected data (Fig. 3b), which may be caused by a hysteresis effect between bedform migration and discharge (Claude et al., 2012; Rodrigues et al., 2015). Moreover, results are sensitive to the computation of the effective bed shear stress since the ratio $K_{s} / K=65 / 28 \approx 2.3$ is relatively large for this specific case.

Concerning the Bm formula, using $\omega=\omega_{\text {simp }}=\rho g Q S_{b} / B$ yields values similar to the "exact" value $\omega=\tau U$ if only the total bed shear stress $\tau$ is used. If $\tau_{\text {eff }}$ is used, it yields values 2.5 times smaller. It is not very physical in the sense that only part of the total bed shear stress is used for transporting sediments (Meyer-Peter and Müller, 1948) but simplifications in Eq. 1 are based on the total bed shear stress. Other differences are mainly due to the estimation of the bed slope, which actually varies significantly with discharge.

A sensitivity analysis of the sediment characteristics on the bedload transport confirmed that bedload is not sensitive to grain size once the critical bed shear stress for inception of transport is largely exceeded (Camenen and Larroudé, 2003). It should 
be noted, however, that for cases where suspended load prevails, transport would be sensitive to grain size because of the settling velocity and sediment diffusion.

\subsection{Yearly averaged sediment transport}

In this section, the models are tested using different representations of the flow duration to investigate its impact on the estimation of yearly averaged sediment transport. The flow duration curve for the hydrometric station at Gien was used for the analysis, and was based on daily discharges measured since 1937 (Fig. 4a). When the relative volumes of water and sediment are plotted as function of the probability of the water discharge (Fig. 4b), it becomes clear that most of the volume of water is transported at relatively normal discharges (i.e. $Q \approx 370 \mathrm{~m}^{3} / \mathrm{s}$, which corresponds to a value slightly larger than the inter-annual average discharge $\left.Q_{I A A}\right)$. The effective discharge $Q_{\text {eff }}$ for the bed-material transport is often described as the discharge at which the largest volume of sediments is transported. Because of non-linearities (critical bed shear stress, $\left.Q_{s b} \propto \tau^{1.5}\right), Q_{e f f}$ is generally much larger for the sediments than for water. In the case of the Loire River at Gien, effective discharge occurs at a relatively low water discharge, e.g. $Q_{\text {eff }} \approx 700 \mathrm{~m}^{3} / \mathrm{s}$ using the CL formula. This is supported by the fieldwork of Claude et al. (2014) who observed significant bed evolutions even during relatively low flow periods and may be explained by the relative low critical bed shear stress for inception of motion for sand particles. For gravel bed rivers, $Q_{\text {eff }}$ corresponds typically to a one-year $(Q 1)$ to two-year $(Q 2)$ return period discharge (Emmett and Wolman, 2001). Model 1 underestimates substantially $Q_{\text {eff }}$ in comparison to Model 2 (Bm and $\mathrm{Cl})$. This is caused by the estimation of $\omega_{\text {simp }}$ based on the total bed shear stress, which significantly reduces non-linearity effects since $\omega_{\text {simp }} \gg \omega_{c r}$.

(a)

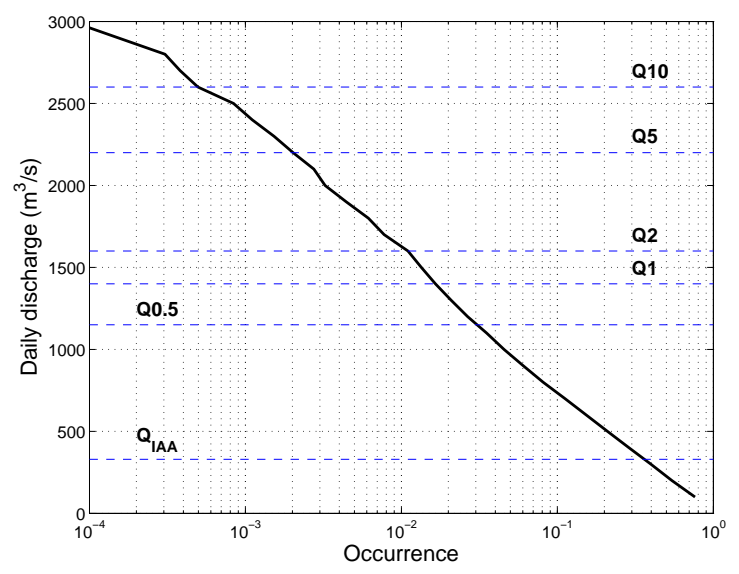

(b)

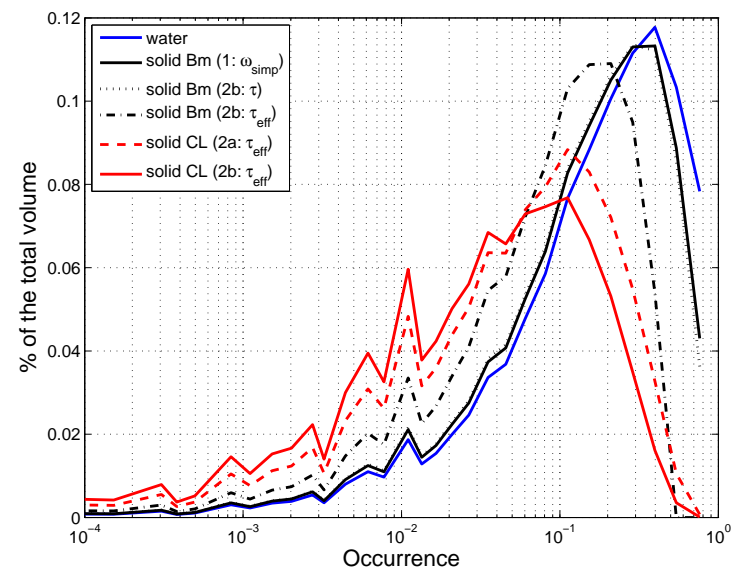

Figure 4: Flow duration curve at Gien (a) and relative volume of water and sediment for different occurrences of the water discharge at Gien (b, see Fig. 3 for details).

In Tab. 1, the yearly averaged volumes obtained from the different methods are presented depending on the description of the flow duration curve: first, $n=30$ with 
Table 1: Estimation of the mean yearly bedload transport on the Loire River at Gien depending on the method and flow duration curve description.

\begin{tabular}{l|c|ccccccc}
\hline \multirow{3}{*}{ Method } & Water & \multicolumn{8}{|c}{ Sediment $\left[10^{6} \mathrm{~kg}\right]$} \\
\cline { 3 - 9 } & {$\left[10^{12} \mathrm{~kg}\right]$} & $\mathrm{Bm}$ & $\mathrm{Bm}$ & $\mathrm{Bm}$ & $\mathrm{CL}$ & $\mathrm{CL}$ & MPM & $\mathrm{VR}$ \\
& & $1: \omega_{\text {simp }}$ & $2 \mathrm{~b}: \tau$ & $2 \mathrm{~b}: \tau_{\text {eff }}$ & $2 \mathrm{~b}: \tau_{\text {eff }}$ & $2 \mathrm{a}: \tau_{\text {eff }}$ & $2 \mathrm{a}: \tau_{\text {eff }}$ & $2 \mathrm{a}: \tau_{\text {eff }}$ \\
\hline$n=30$ & 8.8 & 265 & 222 & 39 & 37 & 71 & 74 & 204 \\
$n=15$ & 11.4 & 340 & 285 & 50 & 46 & 91 & 96 & 270 \\
\hline
\end{tabular}

steps in discharges; second, $n=15$ with steps in frequency as provided in the French data base (http://www.hydro.eaufrance.fr).

Large discrepancy exist in the estimation of the mean yearly bedload transport depending on the method used (Tab. 1). As discussed previously, the Bm formula yields much larger values when using model 1 compared to model 2 with the effective bed shear stress. The description of the flow duration curve has also a significant influence on the results (Lenzi et al., 2006). It is fundamental to include large discharges with very small frequency since a significant sediment transport occurs for these discharges. A rough description ( $n=15$ with steps in frequency) yields biased approximations especially when the efficient discharge corresponds to discharge up to a two-year return period discharge. Calculations were achieved using other classical bedload formulae (MeyerPeter and Müller, 1948; van Rijn, 2007, named hereafter MPM and VR formulae, respectively). The choice of the semi-empirical formula can significantly affect the results. A factor 5 difference exists between the CL (or MPM) and VR formulae, which is much larger than differences observed from the different methods (i.e. model $2 \mathrm{a}$ or $2 \mathrm{~b}$ ) for computing hydraulic parameters.

\subsection{Influence of the grain size longitudinal description on se- diment transport evaluation}

The choice of the longitudinal description of the grain size characteristics may have some influence on the longitudinal variation of the effective bed shear stress and bed load transport. As previously discussed, detailed descriptions of the grain size characteristics are generally lacking for rivers. Fig. 5 showed typical uncertainties one can observe depending on the spatial interpolation made for the grain size. Using a Sternberg law fitted on the whole reach or using a multi-linear fit based on all data available yield some differences in term of bed shear stress and bedload transport estimation along the river reach, but only when the multi-linear fit deviates significantly from the exponential fit (Fig. 2b). Moreover, larger differences are observed depending on the hydraulic calculation (model $2 \mathrm{a}$ versus model $2 \mathrm{~b}$ ). Conceptually, it appears necessary to have a detailed along-stream description of the grain size if one would maintain a system of riffles (with coarser sediments and a steeper slope) and pools (with finer sediments and a milder slope). However, there is often a lack of data for both bathymetry and sediment grain size to describe such in detail a river reach. 


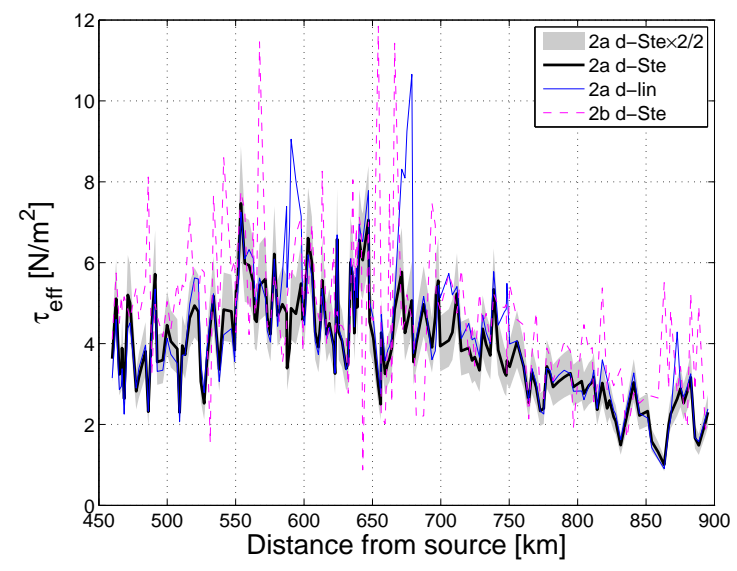

Figure 5: Longitudinal variation of the effective bed shear stress using results from 1D modelling (model 2a) for a 1.5 year return period flood and the Sternberg law (d-Ste) or linear fit (d-lin) for the grain size description or using the Manning Strickler eq. (model 2b) (the gray shade, $2 \mathrm{a}$ d-Ste $\times 2 / 2$, corresponds to the error bar in the $2 \mathrm{a}$ d-Ste plot assuming an error by a factor 2 on the grain size description).

\subsection{Validity of the different methods for the sediment budget}

In order to validate the different models presented, the sediment budgets derived from the models were compared with ones derived from bathymetric surveys for the three reference sites on the Middle Loire River (cf. Fig. 1).

A series of simulations was conducted on these three sites to test the impact of different parameters on the sediment budget (Tab. 2). First, model 1 and 2 were applied on the system of the homogeneous reaches defined in Latapie et al. (2014) for the two descriptions of the grain size distribution along the Middle Loire River, either a linear fit (d-lin) or an application of the Sternberg law (d-Ste), using the flow duration curves measured at the closest hydrometric stations from the three sites. Second, the 1D model RubarBE (model 3) was used to simulated bed evolution during these periods using the set of cross-sections available in the three different sites and the discharge series measured at the closest station. To facilitate comparison with the results from models 1 and 3, the results from the 1D model were spatially averaged for each homogeneous reach.

Table 2: Listing of the different simulations achieved for the three reference sites.

\begin{tabular}{l|clll|l}
\hline Code & Model & Hydraulics & Grain size & Formula & Additional parameters \\
\hline m1dl & 1 & $\omega_{\text {simp }}$ & d-lin & Bm & \\
m1ds & 1 & $\omega_{\text {simp }}$ & d-Ste & Bm & \\
m2dl & $2 \mathrm{~b}$ & MS & d-lin & CL & \\
m2ds & $2 \mathrm{~b}$ & MS & d-Ste & CL & \\
m3ds1 & 3 & 1D & d-Ste & MPM & $E(i) \propto \tau_{i}, D(i) \propto 1 / \tau_{i}$ \\
m3ds2 & 3 & 1D & d-Ste & MPM & $E(i) \propto \tau_{i}, D(i)$ horizontal \\
m3ds3 & 3 & 1D & d-Ste & MPM & $E(i) \propto \tau_{i}, D(i) \propto \tau_{i}$ \\
m3ds1q & 3 & 1D & d-Ste & MPM & $E(i) \propto \tau_{i}, D(i) \propto 1 / \tau_{i}, Q>Q_{c r}$ \\
\hline
\end{tabular}

All results from the simulations are presented in Fig. 6 as reach averaged volumes. 
Model 1 and 2 yield quite similar results overall. They both tend to largely overestimate erosion and deposition volumes and yield poor results even for the general trend (erosion or deposition, Fig. 6 (1a) and (1b)) apart for the Bréhémont case (Fig. 6 (1c)) for which results are consistent with experimental data. This may be explained because of the complexity of the two first sites, which can not be described properly by homogeneous reaches. Indeed, the Belleville sites includes several bridges and weirs that can significantly affect bed evolution. Model 2 with CL formula yields smaller volumes than model 1 (Bm formula), and is more sensitive to the grain size description as discussed previously. For the Guilly case where the simulation time $\Delta t=13$ years, a clear limitation of models 1 and 2 is that bed level is not updated, so long term simulations do not account for possible adjustments. As a conclusion, it appears that both models 1 and 2 do not provide satisfactory results for sediment budgeting as soon as the river presents some complex patterns, neither for long-term modelling.

\subsection{Advantages and limits of the 1D bed evolution modelling}

Simulations using 1D model RubarBE yield satisfactory results once the model is properly calibrated (Fig. 6). For the case of the Middle Loire River, a very long adaptation length has been used $\left(L_{a}=10 \mathrm{~km}\right)$. As discussed by El Kadi Abderrezzak and Paquier (2009), the use of such large values adds some diffusion in the system that is not physical in term of bedload transport but could be attributed to the discrete description of the bathymetry in 1D models, and to the effect of suspended load if not negligible.

For all the simulations listed in Tab. 2, the section-averaged bed shear stress was distributed throughout the river section in order to better estimate the bedload transport (Camenen et al., 2011). However, an important problem in 1D bed-evolution modelling is the method to distribute the computed eroded/deposited volume across the river section. Usually, an eroded volume is distributed as a function of the local bed shear stress $\left(E(i) \propto \tau_{i}\right)$. However, different strategies could be discussed for the deposited volumes (El Kadi Abderrezzak and Paquier, 2009). Deposition is most likely to occur where bed shear stress is lowest $\left(D(i) \propto 1 / \tau_{i}\right)$ but deposition could also follow streamlines $\left(D(i) \propto \tau_{i}\right)$ or be distributed in horizontal layers. Many commercial 1D models assume a symmetrical bed evolution, i.e. distribution for the deposited volumes similar as the one for the eroded volumes. However, results from the three reference sites of the Middle Loire River indicate that a non-symmetrical bed evolution may be more appropriate at least for energetic systems. Indeed, the option $E(i) \propto \tau_{i}$ and $D(i) \propto 1 / \tau_{i}(\mathrm{~m} 3 \mathrm{ds} 1$ and $\mathrm{m} 3 \mathrm{ds} 1 \mathrm{q})$ yields the best results for the three sites (Fig. $62 \mathrm{a}$, $2 \mathrm{~b}$, and $2 \mathrm{c})$.

The description of the discharge time-series is another important issue in numerical modelling. Whereas computations are more or less instantaneous using model 1 or 2 , they can last from several hours to several days depending on the length of the segment with model 3. For the simulation of long timespans, such as a decade (Guilly reference case), a simplification of the discharge time-series was necessary. A simplification made was to limit the modelling to discharges higher than a critical discharge $Q_{c r}$, assuming no significant bed evolution occurs below $Q_{c r}$. For the Middle Loire River, the simplification of the discharge time-series with $Q_{c r}=200 \mathrm{~m}^{3} / \mathrm{s}$ does reduce significantly 
(1a)

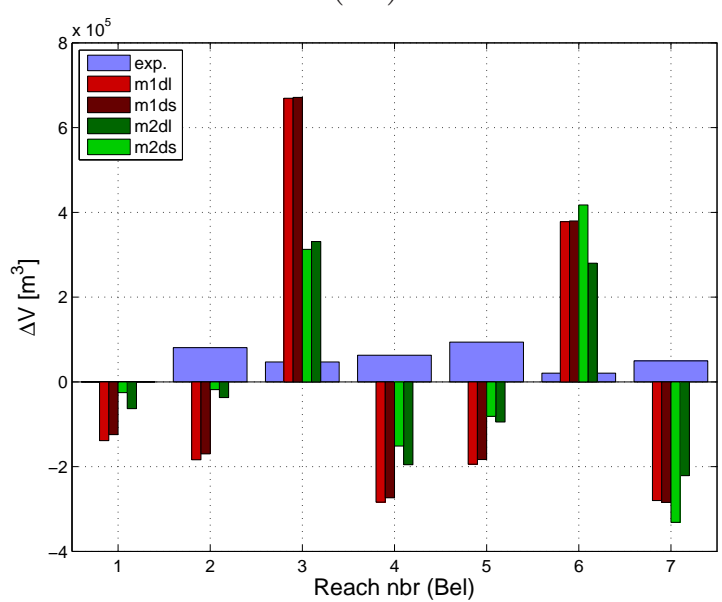

(1b)



(1c)

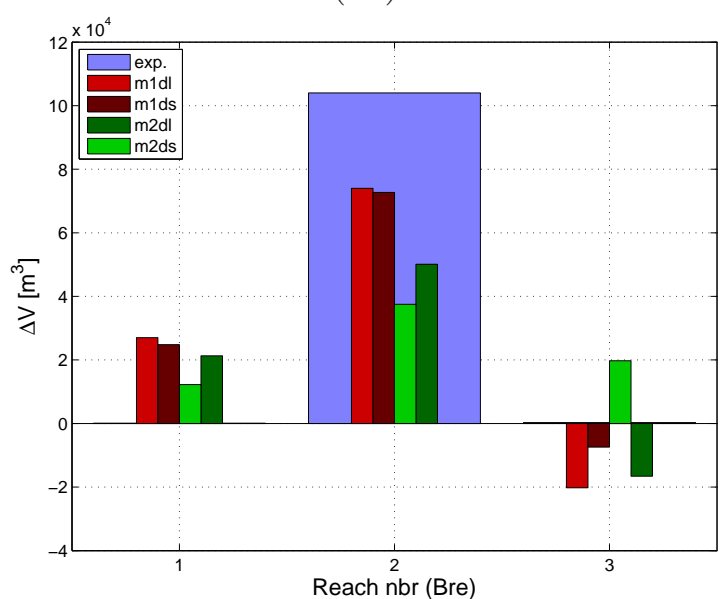

(2a)

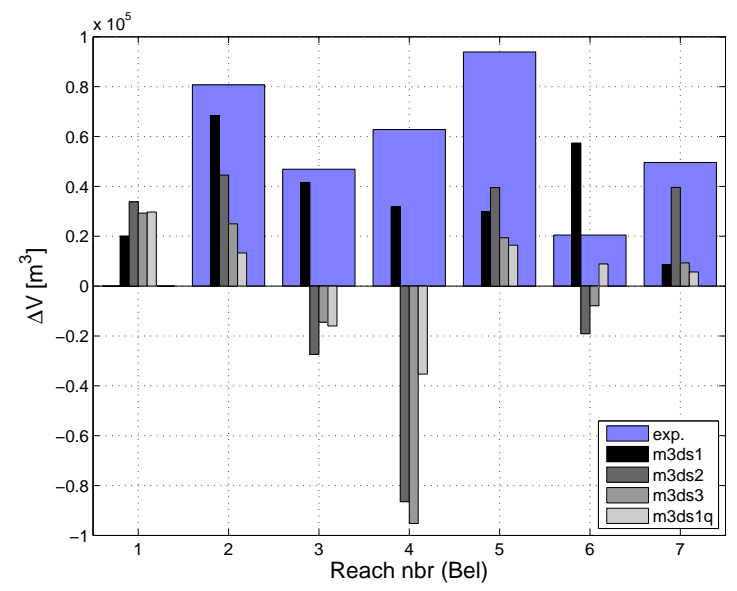

$(2 \mathrm{~b})$

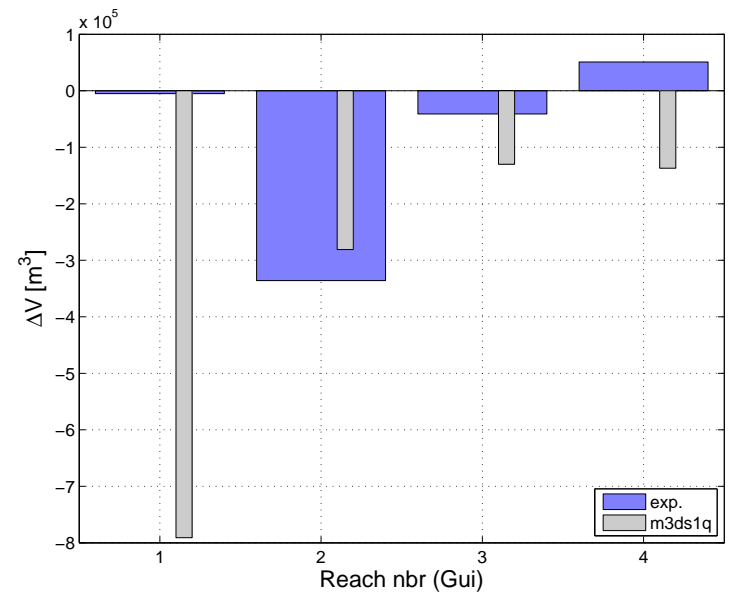

$(2 \mathrm{c})$

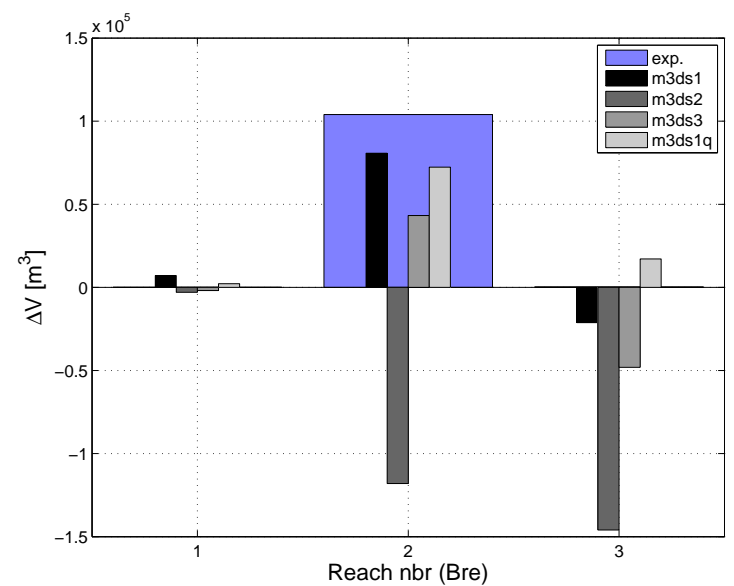

Figure 6: Reach averaged sediment budgets for the three reference sites of Middle Loire River: Belleville $\Delta t=2$ years (a), Guilly $\Delta t=13$ years (b), and Bréhémont $\Delta t=2$ years (c). Comparison between model 1 and 2 (1) and model 3 (2) and experimental measurements (See Tab. 2 for the model details). 
the computation duration but also affects the results (Fig. 6 2a and 2c).

Finally, another related point for modelling using non-uniform flow is that bed evolution is very sensitive to the hydrogram shape and to the organization of the various events (floods) in a discharge time-series. Indeed, using a flow duration with an increasing or a decreasing discharge or the real time-series that was used to built the flow duration curve would yield very different results in term of bed evolution (Latapie, 2011). Following this idea, it seems obvious that models 1 and 2 are not applicable for predicting the future state of a river. Similarly, model 3 may only be applied using a Monte Carlo approach, i.e. by testing a large number of scenarios to validate an averaged trend.

\section{Conclusion}

Bed-material transport and budget are a critical component of the process-based REFORM hierarchical framework and help to inform the assessment of current hydromorphological condition, the river's sensitivity to change, and the future evolutionary trajectories of the river under different management and climate change scenarios (Gurnell

et al., 2015). Given the general lack of sediment transport and bathymetric monitoring data, practitioners will often need to rely on models to supply this information. In this paper, three different methods for estimating bed-material transport and budget were presented and discussed for an application to a long sandy-gravelly segment: the Middle Loire River.

Model 1 is based on the stream power concept (Bagnold, 1966) simplified such as no hydraulic computation is needed. Its application is thus quite simple. It yields reasonable results for the estimation of the sediment transport although poorly sensitive to the grain size since the approach is based on the total bed shear stress and $\omega_{\text {simp }} \gg$ $\omega_{c r}$. Moreover, model 1 does not appear to be well suited to the estimation of sediment budgets, especially in case of complex reaches with anthropogenic structures such as bridge or weirs. Sediment budgets are generally overestimated in term of volume and often incorrect in term of trends (erosion or deposition).

Model 2 includes a more detailed description of the hydraulics using the ManningStrickler equation (or a 1D hydraulic model if possible). This method allows the estimation of sediment transport using other formulae based on the bed shear stress concept. The use of different formulae is interesting since they may yield very different results even if all these formulae are supposed to be applicable for our specific system, and so provide some idea of the uncertainties in bed-material transport and budget estimations. However, model 2 yields results that are very similar to model 1, i.e. reasonable results for the estimation of bedload transport, but poor results for the sediment budget. Thus, whilst models 1 and 2 may be used to generate indicators of sediment transport potential, they should be used with care to discuss segment dynamics.

Finally, model 3, which uses a full 1D hydraulic numerical software with bed evolution, produces the most accurate results for both sediment transport and budget estimations. However, this method requires a more fastidious calibration and validation 
of all the model options (Strickler coefficients, sediment transport formulae, adaptation length, and distribution of the volumes throughout the section). Moreover, the calculation can be time-consuming. Discrepancies between hydrodynamic/sediment transport/bed evolution model predictions and measurements can also be attributed to the oversimplification of the problem (1D), inappropriate or limited input data, lack of appropriate data for model calibration, but also computational errors in source codes. For non-uniform sediments, several phenomena such as grain fining, formation of a armoured layer add some complexity in the sediment transport and bed evolution estimations (Mosselman, 2005; Francalanci et al., 2013). For long-term prediction and testing scenarios, it is possible to use model 3 only if a Monte Carlo approach is used with different scenarios for the distribution of floods along time, respecting the overall flow duration curve.

A summary of the advantages and drawbacks for the three methods discussed in this paper to estimate sediment transport and sediment budget in the Middle Loire River is presented in Tab. 3. Depending on the availability of data and the objectives of a study, it provides an indication of the most suitable model for use in the multi-scale, hierarchical framework for hydromorphology developed within the REFORM project. To properly estimate yearly averaged sediment transport, it is also fundamental to have a long enough discharge time-series to ensure that rare high flow events are included, as they have a substantial impact on sediment transport and morphology. In a similar way, the median grain size distribution along the reach is of importance to properly estimate the bed evolution although results appeared not so sensitive to the longitudinal grain size description for our specific case. One should have in mind that an expertise on the sediment dynamics within the reach is always necessary.

Table 3: Summary of the advantages and drawbacks for the three methods presented to estimate sediment budgets in terms of data requirements and study objectives.

\begin{tabular}{|c|c|c|c|}
\hline Parameters & $\begin{array}{l}\text { Model } 1 \\
\omega_{\text {simp }}\end{array}$ & $\begin{array}{l}\text { Model } 2 \\
\text { MS }\end{array}$ & $\begin{array}{l}\text { Model } 3 \\
1 \mathrm{D} \text { model }\end{array}$ \\
\hline geometrical data needed $^{1}$ & - & $+/-$ & + \\
\hline sediment data needed ${ }^{1}$ & + & ++ & ++ \\
\hline hydraulic data needed ${ }^{1}$ & -- & - & + \\
\hline construction and calibration of the model $^{1}$ & - & $+/-$ & ++ \\
\hline sediment transport estimation $^{2}$ & $+/-$ & + & + \\
\hline sediment budget estimation ${ }^{2}$ & - & - & + \\
\hline computation efficiency $^{2}$ & ++ & + & - \\
\hline predictive capability $^{2}$ & -- & -- & $+/-$ \\
\hline
\end{tabular}

\section{Acknowledgements}

The preparation of this manuscript was supported by the EU FP7 project REFORM (contract no. 282656). We would like to thank E. Mosselman and the three anonymous reviewers for their significant input to improve the quality of this paper. 


\section{References}

Bagnold, R. A. (1966). An approach of sediment transport model from general physics. Technical Report 422-I, US Geol. Survey Prof. Paper.

Brewer, P. A. and Passmore, D. G. (2002). Sediment budgeting techniques in gravelbed rivers. In Jones, S. and Frostick, L. E., editors, Sediment Flux to Basins: Causes, Controls and Consequences, volume special publications 191, pages 97-113, London, UK. Geological Society.

Camenen, B. (2012). Discussion of "understanding the influence of slope on the threshold of coarse grain motion: Revisiting critical stream power" by C. Parker, N.J. Clifford, and C.R. Thorne. Geomorphology, 139-140:34-38.

Camenen, B., Holubová, K., Lukač, M., Le Coz, J., and Paquier, A. (2011). Assessment of methods used in 1D models for computing bedload transport in a large river: the Danube River in Slovakia. J. Hydraulic Eng., 137(10):1190-1199.

Camenen, B. and Larroudé, P. (2003). Comparison of sediment transport formulae for a coastal environment. Coastal Eng., 48:111-132.

Camenen, B. and Larson, M. (2005). A bedload sediment transport formula for the nearshore. Estuarine, Coastal \& Shelf Science, 63:249-260.

Claude, N., Rodrigues, S., Bustillo, V., Bréhéret, J.-G., Macaire, J.-J., and Jugé, P. (2012). Estimating bedload transport in a large sand-gravel bed river from direct sampling, dune tracking and empirical formulas. Geomorphology, 179:40-57.

Claude, N., Rodrigues, S., Bustillo, V., Bréhéret, J.-G., Macaire, J.-J., and Jugé, P. (2014). Interactions between flow structure and morphodynamic of bars in a channel expansion/contraction, Loire River, France. Water Resources Res., 50:2850-2873.

Daubert, A. and Lebreton, J. C. (1967). Etude expérimentale et sur modèle mathématique de quelques aspects des processus d'érosion des lits alluvionnaires, en régime permanent et non-permanent [Study with a mathematic model on some erosion processes in alluvial rivers for steady and unsteady regimes]. In Proc. 12th IAHR Congress, volume 3, pages 26-37, Fort Collins, Colorado, USA. (in French).

El Kadi Abderrezzak, K. and Paquier, A. (2009). One-dimensional numerical modeling of sediment transport and bed deformation in open channels. Water Resources Res., 45(W05404):20 p.

Emmett, W. W. and Wolman, M. G. (2001). Effective discharge and gravel-bed rivers. Earth Surface Proc. \& Landforms, 26:1369-1380.

Francalanci, S., Paris, E., and Solari, L. (2013). A combined field sampling-modeling approach for computing sediment transport during flash floods in a gravel-bed stream. Water Resources Res., 49:6642-6655. 
Francalanci, S., Solari, L., Toffolon, M., and Parker, G. (2012). Do alternate bars affect sediment transport and flow resistance in gravel-bed rivers? Earth Surface Proc. 86 Landforms, 37:866-875.

Frings, R. M. and Kleinhans, M. G. (2008). Complex variations in sediment transport at three large river bifurcations during discharge waves in the river Rhine. Sedimentology, 55:1145-1171.

Grabowski, R. C. and Gurnell, A. M. (2015). Diagnosing problems of fine sediment delivery and transfer in lowland, Northwest European catchments: The Frome catchment, southern England. Aquatic Sciences, this volume.

Grabowski, R. C., Surian, N., and Gurnell, A. M. (2014). Characterizing geomorphological change to support sustainable river restoration and management. WIREs Water, 1(5):483-512.

Gurnell, A., Bussettini, M., Camenen, B., González del Tánago, M., Grabowski, R., Hendriks, D., Henshaw, A., Latapie, A., Rinaldi, M., and Surian, N. (2014). A multi-scale framework and indicators of hydromorphological processes and forms. Deliverable 2.1, Part 1, REFORM (REstoring rivers FOR effective catchment Management), a Collaborative project (large-scale integrating project) funded by the European Commission within the 7th Framework Programme under Grant Agreement 282656. 217p.

Gurnell et al., A. M. (2015). A multi-scale hierarchical framework for developing understanding of river behaviour to support river management. Aquatic Sciences, this volume.

Latapie, A. (2011). Modélisation de l'évolution morphologique d'un lit alluvial: application à la Loire Moyenne [Modelling the morphological evolution of the Middle Loire River (France)]. PhD thesis, F. Rabelais University, Tours, France. 279 p. (in French).

Latapie, A., Camenen, B., Rodrigues, S., Paquier, A., Bouchard, J.-P., and Moatar, F. (2014). Classifying anthropogenised river reaches to assess channel changes using hydraulic parameters. Catena, 121:1-12.

Lenzi, M. A., Mao, L., and Comiti, F. (2006). Effective discharge for sediment transport in a mountain river: Computational approaches and geomorphic effectiveness. $J$. Hydrology, 326:257-276.

Meyer-Peter, E. and Müller, R. (1948). Formulas for bed-load transport. In Proc. 2nd IAHR Congress, pages 39-64, Stockholm, Sweden.

Mosselman, E. (2005). Modelling sediment transport and morphodynamics of gravelbed rivers. In Church, M., Biron, P., and Roy, A., editors, Gravel-Bed Rivers VII: Processes, Tools, Environments, pages 101-115. Wiley \& sons. 
Papanicolaou, A. N., Elhakeem, M., Krallis, G., Prakash, S., and Edinger, J. (2008). Sediment transport modeling review - current and future developments. J. Hydraulic Eng., 1:1-14.

Parker, C., Thorne, C. R., and Clifford, N. J. (2014). Development of ST:REAM: a reach-based stream power balance approach for predicting alluvial river channel adjustment. Earth Surface Proc. \& Landforms, 40(3):403-413.

Pitlick, J. and Wilcock, P. (2001). Relations between streamflow, sediment transport, and aquatic habitat in regulated rivers. In Dorava, J. M., Montgomery, D. R., Palcsak, B. B., and Fitzpatrick, F. A., editors, Geomorphic Processes and Riverine Habitat, Washington, D. C. American Geophysical Union.

Reid, L. M. and Dunne, T. (1996). Rapid evaluation of sediment budgets. GeoEcology. Catena Verlag, Reiskirchen. ISBN: 3-923381-39-5.

Rodrigues, S., Mosselman, E., Claude, N., Wintenberger, C., and Jugé, P. (2015). Alternate bars in a sandy gravel bed river: generation, migration and interactions with superimposed dunes. Earth Surface Proc. \&5 Landforms, 40(5):610-628.

Sternberg, H. (1875). Untersuchungen über längen- und querprofil geschiebeführender flüsse [Study on the longitudinal and transversal bed-load transport in rivers]. Zeitschrift Bauwesen, 25:483-506. (in German).

Surian, N. and Rinaldi, M. (2003). Morphological response to river engineering and management in alluvial channels in Italy. Geomorphology, 50:307-326.

Valverde, L., Rodrigues, S., Jugé, P., Desmet, M., Recking, A., and Tal, M. (2013). Variations of grain size in relation with cross-section dynamics and tributary confluences in a large sand-gravel bed river: the Loire (France). In Proc. 8th International SedNet conference, Lisbon, Portugal.

van Rijn, L. C. (2007). Unified view of sediment transport by currents and waves. I: Initiation of motion, bed roughness, and bed-load transport. J. Hydraulic Eng., 133(6):649-667.

Wilcock, P. R. (2001). Toward a practical method for estimating sediment transport rates in gravel-bed rivers. Earth Surface Proc. E5 Landforms, 26:1395-1408.

Wu, W., Viera, D. A., and Wang, S. S. Y. (2004). One-dimensional numerical model for nonuniform sediment transport under unsteady flows in channel networks. $J$. Hydraulic Eng., 130(9):914-923. 